\title{
Transference:
} \section{keeping mum or mummified?}

\author{
James Johnston
}

\begin{abstract}
SUMMARY
Transference reveals the mental state of the other to us through our countertransference. Our emotional responses to the transference relationship are different depending on the degree of disturbance evoked in us. Reflecting on our countertransference can convey emotional insight into the nature and meaning of the transference as a way of understanding the emotional experiences of the other.
\end{abstract}

\section{DECLARATION OF INTEREST}

None.

Transference is a psychoanalytic concept which describes the emotional echo belonging to a past relationship being re-experienced in a relationship in the present. Transference is revealed through the countertransference, the experience of the patient traced through their emotional impact on the professional. The reawakening of the past in the present is unconscious and may be consciously experienced in the relationship or may remain unconscious, manifest in enactments.

Feelings are in constant dynamic flux in relationships, and the experience of being moved in mind can be represented in the physical sense of being moved in body.

\section{Psychotic and non-psychotic transference}

A non-psychotic transference from patients to professionals is felt in the countertransference as an emotional echo, a reminder: this is the experience of empathy. This is a discomforting but quotidian feeling of being moved, or bumped into, an ordinary walking-pace collision, a pedestrian countertransference.

A psychotic transference is a disturbing and violent mental impact which is not consciously recognised, but is rapidly, viscerally and unexpectedly experienced. This is being not so much moved as psychically knocked down and rendered unconscious. It is a mental 'hit and run' by an anonymous, fast-moving assailant who is experienced as alien. It feels more like colliding with a car on a road than bumping into another human being on a pavement. The psychotic transference is a dangerous and alienating experience that leaves bleeding empathy behind as the road-kill of life, a car-crash countertransference.

The accompanying cartoon (Fig. 1) is a sort of Trojan horse, containing the unconscious twin treats and threats of infancy - a Trojan mummy, perhaps (Johnston 2007). The 'mummy therapist' carries a message about an unseen enemy of empathy. The Psychic Warrior shows the twin concepts of transference and countertransference. The therapist sits completely wrapped in bandages, saying to an empty space: 'Wrapping me up in bandages doesn't make me your mummy, does it, Mr. Jones? Mr. Jones?'

A psychic assault on the therapist has taken place and the patient has fled the scene, leaving a mummified therapist. The bandages wrapping the therapist head to toe symbolise both an attempt at manic repair and a covering up of the damage caused to mind and body. The absence of the patient is a flight from recognition of harm done, with the experience of guilt erased by the object of assault being out of sight, out of mind. The therapist calls out to a patient who has gone, a countertransference echo of the loss the patient defends against through their fight and flight.

'Keeping mum' can mean being silent or it can mean holding on to mother in an Oedipal sense. It is the silent operation of an unspoken relationship, an echo of the past in the present, expressed in transference to professionals on a developmental spectrum between mind and body, non-psychotic transferences to psychotic transferences.

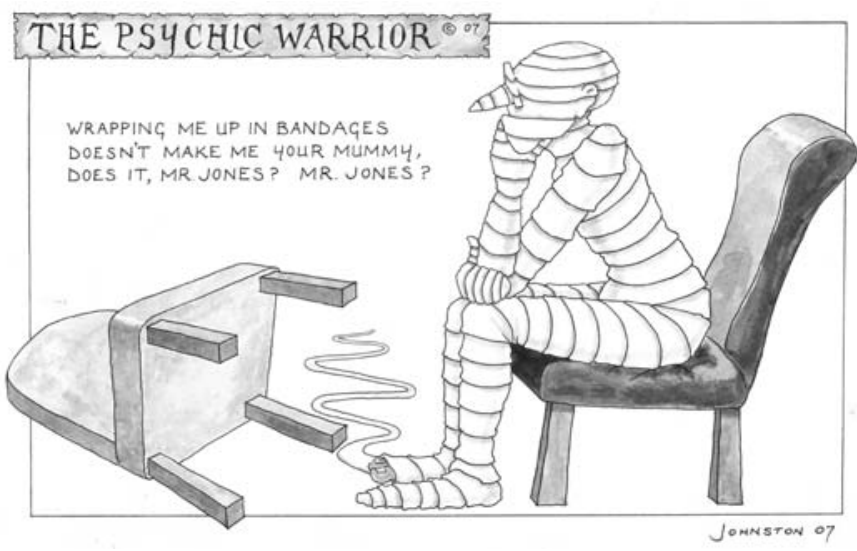

FIG 1 A Trojan mummy, embodying the twin concepts of transference and countertransference. (C) 2007 James Johnston.
James Johnston is a consultant psychiatrist in psychotherapy and the medical psychotherapy lead with Leeds Partnerships NHS Foundation Trust. He is also current Chair of the Education and Curriculum Committee of the Royal College of Psychiatrists' Medical Psychotherapy Faculty. Correspondence Dr James Johnston, Medical Psychotherapy Consultation Service, Southfield House, 40 Clarendon Road, Leeds LS2 9PJ, UK. Email: James. Johnston2@nhs.net 
The psychotic transference and intense destructive use of the body can evoke a painful, visceral emotional response, which has to be defensively numbed as a disturbing countertransference. This is manifest in professionals who tend to turn a blind eye to the mind, who turn away from the possible meaning of being disturbed towards a predominantly organic or bodily view, mummifying mental pain. Rather like the Psychic Warrior, the damage is wrapped up in the bandages of physical treatment.
Psychiatrists who resist keeping mum about their countertransference and see it as relevant to understanding the meaning of their patients' experiences could be the reason why transference resists being mummified as a psychoanalytic relic fit only for the British Museum.

\section{Reference}

Johnston J (2007) The Psychic Warrior. In 'Drawing from Life: Psychoanalytic Pictures of Psychiatry'. Royal College of Psychiatrists (http://www. rcpsych.ac.uk/training/studentassociates/perspectivesonpsychiatry/ drawingfromlife.aspx). 